\title{
Diálogo e interação na produção de textos na escola: análise de um evento de letramento
}

\author{
Maria do Socorro Alencar Nunes Macedo ${ }^{1}$ \\ Érica Feijó de Lima²
}

\section{Resumo}

Este artigo tem como objetivo refletir sobre letramento na escola com o foco na produção de textos de alunos do terceiro ano do ensino fundamental. Tomamos como base teórico-metodológica os novos estudos do letramento (NEL) articulada à perspectiva enunciativa da linguagem proposta por Bakhtin. A pesquisa realizou-se por meio de observações com gravações de áudio, registro no diário de campo e entrevista semiestruturada com a docente. Os resultados indicam uma forma dialógica de mediação da professora no trabalho com a língua escrita em uma turma que está finalizando o ciclo de alfabetização, a partir da análise da escrita de um bilhete, evento de letramento muito comum nesse contexto escolar.

Palavras-chave: Letramento; Produção de textos; Diálogo; Interação.

Dialogue and interaction in the writing texts in school: analysis of a literacy event

\section{Abstract}

This article discusses on school literacy focusing on the process of writing texts by the third-year students of elementary school. As a theoretical-methodological basis we take the new studies of literacy (NLS) articulated to an enunciative view of language proposed by Bakhtin. The research, was carried out through observations with audio recordings, field notes and semi-structured interview with the teacher. The results indicate a dialogic form of the teacher's mediation in a classroom that is finishing the literacy cycle, in the process of writing a notice to the parents, a very common literacy event in the school context.

Keywords: Literacy; Writing texts; Interaction; Dialogue.

\section{Introdução}

Muitos autores têm se debruçado sobre a relação entre letramento e escolarização e sobre práticas de letramento na escola (SCRIBNER; COLE, 1981; HEATH, 1983; COOK-GUMPERZ, 1991; MACEDO, 2005, BUNZEN, 2010, STREET, 2014, por exemplo), compreendendo o letramento na escola como uma prática social dentre as diversas manifestações do letramento na sociedade. Nesta perspectiva o letramento deve ser percebido no plural por que muda de acordo com o contexto e é marcado ideologicamente. Para Kleiman (1995), as práticas escolares

\footnotetext{
${ }^{1}$ Universidade Federal de São João del-rei, São João del-rei, socorronunes@ufsj.edu.br

2 Universidade Federal de Pernambuco, Recife, ericafeijolima.ef@gmail.com
} 
de uso da leitura e da escrita baseiam-se numa concepção autônoma de escrita como um produto descontextualizado sendo a sua aprendizagem um processo individual. Contrapondo-se a essa concepção, Bunzen (2010) nos alerta sobre o uso do termo letramento escolar como algo negativo ou perverso, autônomo e estático por natureza e defende que o letramento escolar seja compreendido como um conjunto de práticas socioculturais, que possui uma forte relação com os processos de aprendizagem formal da leitura e da escrita e que as práticas de letramento ocorrentes nessa esfera refletem a cultura escolar e apresenta cenas de letramento específicas que carregam as características da escola como instituição.

Dois conceitos gestados na perspectiva dos NEL têm sido bastante utilizados na pesquisa sobre letramento na escola. O primeiro é o conceito de eventos de letramento, cunhado por Heath (1983, p.93) segundo a qual "um evento de letramento é qualquer situação em que um portador qualquer de escrita é parte integrante da natureza das interações entre os participantes e de seus processos de interpretação".

A autora considera eventos de letramento as cenas em que as relações sociais com a escrita ocorrem. É a cena, o dado observável, na qual a escrita estabelece determinadas práticas, ou seja, o evento retrata a relação entre as pessoas e a linguagem escrita. O conceito de práticas de letramento amplia e complementa o conceito de eventos denominadas como "[...] os modos culturais gerais de usar a leitura e a escrita que as pessoas produzem num evento de letramento" (BARTON, 1994, p.7).

Diferentes estudos, cujo objeto são as ações pedagógicas que tratam da produção de textos na escola (LEAL, 2004; GUERRA, 2009; CRUZ, 2012; GIRÃO \& BRANDÃO, 2011; VARELLA, 2013; ANDRADE, 2015), demonstram que, na maioria das vezes, essas ações têm limitado as possibilidades de os estudantes apreenderem as condições de produção de textos, as especificidades e as finalidades de textos produzidos na sociedade, como se observa na ponderação de Guerra (2009):

Ensinar a produzir textos realmente não é tarefa fácil, pois exige que o próprio professor tenha consciência sobre as estratégias necessárias e sobre as dimensões de textualidade que precisam ser objeto de reflexão do aluno, ou seja, tanto o professor quanto o aluno precisam ter consciência de que no processo de produção de texto, se faz necessário planejar e executar as ações tanto no plano geral, que diz respeito à ideia central do texto e à estrutura geral, como também nos planos específicos, relativos às partes do texto. Eles devem

Periódico Horizontes - USF - Itatiba, SP - Brasil - e020005 
estar atentos às particularidades dos diversos elementos que compõem o texto (GUERRA, 2009, p. 14).

Em um ensino alicerçado na concepção de linguagem como interação (BAKHTIN/VOLOCHINOV, 1995 [1929]) é premissa básica da ação pedagógica considerar a língua uma ferramenta cultural socialmente produzida. O dialogismo bakhtiniano fundamenta-se numa concepção de linguagem como prática social, marcada ideologicamente, construída no processo de interação verbal entre sujeitos socialmente organizados. Para o autor, o diálogo é o traço fundamental da enunciação e ultrapassa a interação face-a-face. "Pode-se compreender o diálogo num sentido amplo, isto é, não apenas como a comunicação face-a-face, mas toda comunicação verbal de qualquer tipo que seja". Bakhtin afirma que "toda enunciação mesmo na forma imobilizada da escrita é uma resposta a alguma coisa e é construída como tal" (BAKHTIN/VOLOCHINOV, 1995, p. 98). Nas palavras do autor,

\begin{abstract}
O livro, isto é, o ato de fala impresso, constitui igualmente um elemento da comunicação verbal. Ele é objeto de discussões ativas sob a forma de diálogo, e, além disso, é feito para ser apreendido de maneira ativa, para ser estudado a fundo, comentado e criticado no quadro do discurso interior, sem contar a reações impressas, institucionalizadas, que se encontram nas diferentes esferas da comunicação verbal (criticas, resenha, que exercem influência sob os trabalhos posteriores, etc.). [...] assim, o discurso escrito é de certa maneira parte integrante de uma discussão ideológica em grande escala: ele responde a alguma coisa, refuta, confirma, antecipa as respostas e objeções potenciais, procura apoio, etc. (BAKHTIN/VOLOCHINOV,1995, p.123).
\end{abstract}

Dessa forma, as práticas constituintes do letramento na escola devem se aproximar das práticas e usos de outros contextos sociais da escrita. Ao analisarmos o uso da escrita em nosso cotidiano, percebemos a existência de finalidades e interlocutores em nossas interações, sejam das mais simples como: anotar algo na agenda, redigir um bilhete, enviar mensagens, e-mails, até as mais complexas, como redigir um artigo científico e escrever uma carta de reclamação à prefeitura. Dessa forma, acreditamos que no contexto escolar os usos situados e contextualizados da escrita devem ser objeto de atenção das práticas pedagógicas.

Nesse sentido, Geraldi (1997) considera que para produzir um texto é necessário que se tenha não somente o que escrever, mas também para que e para quem escrever. Tais informações servirão para orientar o estudante tanto na escolha do gênero textual como na escolha dos recursos linguísticos a serem utilizados. 
Como alertam Girão e Brandão (2011, p. 126):

Escrever um cartão de aniversário para a diretora, um bilhete para os pais, histórias para compor um livro [...] o importante é que a escrita apresente uma finalidade clara e um destinatário, sendo explicitado um gênero textual a ser produzido. É por meio desse contexto chamado de condições de produção textual, que as crianças podem pensar sobre quem, para que o que escrevemos assim como, de fato, fazemos nos diversos momentos de nossa vida em que nos deparamos com a tarefa de escrever um texto.

Ao analisar a contribuição das autoras podemos perceber a relação estabelecida entre as condições de produção e usos da escrita, que é um modo de interação entre as pessoas no qual existe um motivo que nos impulsiona a escrever, interagimos com alguém através da escrita e esse registro escrito comumente possui uma forma socialmente estabilizada. Proporcionar atividades na escola que possibilitem um ensino de produção de texto, buscando promover as condições de produção, é ir de encontro ao que denunciam Góes e Smolka (1992). As autoras explicitam que é comum em práticas de produção de texto na escola, onde a finalidade da escrita é o exercício, e o professor o único destinatário, que corrige e avalia a produção, a partir de certos critérios por ele selecionados, o empobrecimento da interação e as possibilidades de destinação do que foi redigido. Este artigo tem como objetivo refletir sobre letramento na escola com o foco na produção de textos de alunos do terceiro ano do ensino fundamental. Tomamos como base teórico-metodológica os novos estudos do letramento (NEL) articulada à perspectiva enunciativa da linguagem proposta por Bakhtin/Volochinov (1995 [1929]).

\section{Metodologia}

Realizamos a pesquisa alicerçada em pressupostos pesquisa qualitativa com a incursão no campo, por meio de observações com gravações de áudio, registro no diário de campo e entrevista semiestruturada.

Pesquisas sobre as práticas da leitura e da escrita na escola (MACEDO, 2005; COSTA, 2010; MARINHO, 2010; CHAGAS, 2011; BUNZEN, 2014) têm contribuído para a compreensão e a visibilidade de elementos muitas vezes imperceptíveis na prática de professores, na vida dos estudantes e no cotidiano escolar. 
Compreendemos a pesquisa qualitativa como uma perspectiva que ultrapassa a mera descrição, com a exigência de um conjunto de observações, questionamentos, olhares e reflexões que nos permitem construir uma visão ampla dos fenômenos ocorridos na sala de aula, na busca de nos afastarmos de um olhar etnocêntrico sobre a cultura da sala.

Em nossa incursão no campo, nos comprometemos com a perspectiva êmica que, segundo Green, Dixon, Zaharlick (2005) busca compreender os significados de práticas vividas pelo sujeito a partir da visão que ele próprio tem a respeito dessas práticas. Buscamos "evidenciar a voz" do sujeito desta pesquisa, uma professora do 3 o ano do ensino fundamental.

As observações da sala de aula realizaram-se entre fevereiro e maio do ano de 2016 numa escola pública da rede municipal de Recife, localizada na periferia da cidade, que atende a crianças das camadas socialmente, e economicamente desfavorecidas. Foram 19 observações realizadas com foco direcionado na produção de textos, as aulas observadas atenderam aos diversos componentes curriculares, não se restringindo às aulas de língua portuguesa. Desse total, registramos apenas 5 aulas em que a produção de textos ocorreu. Mesmo estando presente no lócus da pesquisa, por si só, não era suficiente, o uso da observação configurou-se um elemento potencializador da compreensão da realidade investigada.

A observação da sala de aula apontou questionamentos e surgiu a necessidade de entrevistar a professora. Foram realizadas duas entrevistas: a primeira ocorreu logo no segundo encontro com a professora, em sua própria sala de aula, bem no início do ano letivo em 11 de fevereiro de 2016. Já o segundo momento foi planejado após a conclusão das observações, reescrita do diário de campo, transcrição de áudios e construção dos mapas de eventos, com a intenção de clarear e aprofundar nossas considerações sobre os eventos de letramento observados de maneira geral, e especificamente no ensino de produção de textos mediados pela professora.

\section{Resultados e discussão}

A estrutura física da escola é composta por uma área com sete salas de aula, sala dos professores com uma boa estrutura, climatizada e com mobília adequada. Em 2016 a escola atendeu ao total de 249 estudantes. Desse total, 34 na Educação Infantil e os outros 215 matriculados nos Anos Iniciais do Ensino Fundamental, distribuídos num total de 13 turmas. A 
professora da turma cursou Licenciatura em Ciências e Matemática tendo feito o curso de magistério de nível médio. Mostrou-se uma professora atenta à turma, orientava as crianças nos momentos de realização das atividades, sempre circulava pela sala atendendo às crianças de mesa em mesa tirando dúvidas quando solicitada. Permitia e incentivava que as crianças mais ágeis ajudassem aos colegas a concluírem as atividades, evidenciando uma compreensão de que a aprendizagem é um processo de natureza social, que se dá na interação. Exigia escrita legível e caderno organizado; sempre olhava caderno por caderno ao fim de cada atividade.

A professora afirmou que os materiais que usava com as crianças, em sua maioria, eram impressos com recursos próprios. Ela justificou que, às vezes, a impressão fornecida pela escola, devido à escassez de recursos financeiros, não era boa, o que dificultava a legibilidade e, consequentemente, a realização das atividades. Então, preferia imprimir as atividades em casa fazendo uso de papel ofício branco. Não utilizava o papel ofício reciclável, comumente oferecido na escola, por ser escuro - com tom de cor amadeirada -, considerava o material inadequado para imprimir atividades para as crianças. Esse dado evidencia o impacto das questões materiais sobre a prática docente, fazendo que a professora busque uma alternativa para suprir a limitação de recursos financeiros da escola, decidindo utilizar recursos próprios, indício da precarização na educação básica.

A sala de aula possui 25 conjuntos mobiliários formados por carteiras e cadeiras, um birô, dois armários, um deles fechado, outro com livros didáticos da professora e um quantitativo grande de livros didáticos que ainda estavam lacrados destinado as crianças, dois expositores de livros de literatura infantil, um armário com alguns brinquedos organizados, e em um canto da sala alguns materiais produzidos pela professora pendurados em um cabide. Nas paredes, estavam expostos dois alfabetários distintos, um deles em caixa alta, já o outro, confeccionado a partir de impressões das letras em papel ofício, com as diversas formas da mesma letra acompanhada de uma figura colorida cujo nome é iniciado pela letra em evidência. Ainda, um expositor numérico em formato de centopéia, com a sequência numérica de 1 a 69. Também estavam expostos um calendário anual e um quadro de aniversariantes.

Das 21 crianças, 7 já tinham sido seus alunos nos anos anteriores. Um ponto que chamou nossa atenção refere-se ao contingente de crianças que iniciaram o ano letivo de 2016 com resultado de retenção no ano anterior, no total de 11 crianças, 8 do sexo masculino e 3 do sexo 
feminino, 10 delas oriundas da própria escola. Os materiais e recursos pedagógicos aqui indicados são bastante comuns em salas de aula dos anos iniciais do EF, exceto a presença de expositores de livros literários, que, em muitas salas de aula se encontram ausentes ou inacessíveis às crianças, como mostram pesquisas de MACEDO (2005) e Almeida (2012).

\section{Produzindo um bilhete para os pais}

Dos cinco eventos de produção de textos observados nesta turma, selecionamos para discussão neste artigo a escrita de um bilhete para os pais, situação bastante comum em turmas dos anos iniciais. A produção teve como agente mobilizador um "problema" do cotidiano escolar. Era necessário informar aos pais sobre a primeira reunião do ano letivo, que tinha por objetivos a entrega dos kits escolares destinados às crianças advindos da Secretaria de Educação do Recife e tratar de assuntos peculiares a vida escolar das crianças. A professora, sabendo que naquele dia a copiadora da escola estava com problemas, decidiu realizar a produção escrita de um bilhete para o atendimento dessa demanda. Observamos novamente a influência das condições materiais da escola na definição dos recursos pedagógicos a serem utilizados: escrever um bilhete porque não havia condições para a impressão ou cópia de uma correspondência da escola.

O momento de produção coletiva do texto aconteceu no dia 04 de março de 2016, nossa 4a observação de aula. Ao analisarmos os eventos descritos no diário de campo, temos como primeiro ponto relevante a escrita do cabeçalho antecedendo a produção do bilhete, forma de escrita que se repetiu em todas as aulas. Esse fato expressa o espaço relevante que esse tipo de escrita tem na constituição das práticas de letramento na turma investigada. Isso inquietou-nos por se tratar de uma produção escrita destinada aos pais, um bilhete, que usualmente em outros contextos, não se compõe de um elemento formalizador como um cabeçalho.

Sobre a escrita coletiva do bilhete, nos chamou atenção o contexto de produção desse gênero externado na iniciativa da professora ao propor a produção coletiva em detrimento da "cópia" do bilhete como pontuou em entrevista:

"Surgiu de uma necessidade de mandar avisar as mães, a escola estava sem toner, eu ia, se eu escrevesse e dissesse "vamos escrever", era uma coisa que talvez eles não dessem tamanha importância, na hora que eles constroem ele 
vai chegar em casa, mesmo que a letra não esteja muito desenhada, não esteja tão perceptível que a mãe possa ler, mas ele sabe o que é que foi trabalhado, ele sabe o que é que aquele bilhete dizia, porque ele participou daquela construção, ele era o construtor daquele bilhete, não foi a professora que mandou copiar" (Entrevista com a professora, 24 de outubro de 2016, Recife$P E)$.

Como já evidente, o trabalho com o bilhete não estava inserido no planejamento da professora. A necessidade dessa escrita surgiu devido a um contratempo do cotidiano escolar, porém a escolha da produção coletiva do texto evidencia a sensibilidade da professora para o trabalho contextualizado com a escrita, elemento fundamental da concepção de escrita como uma prática social, como discute Street (1984). Para ela, a participação no processo de produção asseguraria às crianças a percepção de elementos constitutivos do gênero, ou seja, das condições de produção de um bilhete (GERALDI, 1997). Quando afirmou que "ele sabe o que foi trabalhado, ele sabe o que o bilhete dizia, por que ele participou daquela construção", a professora indicou que a participação efetiva das crianças na produção do texto possibilitaria uma maior compreensão das informações ali contidas, em detrimento da "cópia”, quando afirmou que: “[...] se eu escrevesse e dissesse vamos escrever [aqui a professora se referiu a cópia, caso não optasse pela produção coletiva], era uma coisa que talvez eles não dessem tamanha importância [...]". Isso indica a estratégia de envolver as crianças por meio da interação com uma prática real de produção escrita e não uma tarefa escolar distante dos interesses das crianças.

Ao analisarmos a ação pedagógica da professora, percebemos que, mesmo sem um planejamento efetivo para a produção coletiva desse texto, o contexto para a produção partiu de uma necessidade real de comunicação e as condições de produção textual incluíram três elementos básicos: finalidade da escrita (avisar aos pais sobre a reunião), um interlocutor real (os pais das crianças) e um gênero a ser produzido (o bilhete). No diálogo que segue, poderemos compreender melhor como as condições de produção da escrita materializaram-se neste evento de letramento (HEATH, 1983).

Apresentaremos abaixo o diálogo da professora com a turma, relativo ao momento de produção coletiva do gênero bilhete, constituído por 39 turnos de fala, numerados para facilitar a retomada nas análises. A legenda é: P-professor; Als - alunos; A - aluno (a). 
1. P: Olhe, vejam bem, a gente vai ter que convocar mamãe para vir na escola. Por que as mães estão vindo a escola?

2. Als: Para reunião [Em coro]

3. P: Para que essa reunião?

4. Als: Para dá os materiais! [Em coro]

5. P: Isso, para receber os materiais. As outras turmas já vieram, não foi? Tá faltando algumas, inclusive a nossa turma, mas para que mamãe possa vir, a gente precisa fazer o que?

6. Als: Levar um bilhete avisando. [Algumas crianças]

7. P: Então, nós vamos escrever um bilhete avisando. Para quem?

8. A: Para mamãe

9. P: Então vou colocar o nome aqui, oh, para quem vai o bilhete... [Escreveu no quadro a palavra Mamãe - centralizado] e se não tiver mamãe, ou caso ela não esteja em casa, vai paraquem?

10. Als: Para o papai! [Algumas crianças em coro]

11. P: E então, o que eu posso dizer aqui... Mamãe ou papai [Retificou no registro do quadro o destinatário, escreveu uma barra, (/) e logo após a palavra papai].

12. P: O que mais eu posso dizer nesse bilhete, quem pode me ajudar? Como é que eu digo?

13. A: Eu, eu,

14. P: Vai, $C$

15. A: Mamãe venha receber o material de seu filho!

16. P: Todo mundo concorda?

17. Als: Sim! [Em coro]

18. P: É isso mesmo? Ou tem mais alguma coisa...já sei é bem para dizer que vocês estão trelosos..

19. Als: Não, é para pegar os materiais! [Algumas crianças]

20. P: Então, vamos botar aqui...

[Virou-se para o quadro e registrou Mamãe, venha receber o material de seu filho]

21. P: É assim, C? Todo mundo concorda, né? Será que ela vai entender esse bilhete?

22. Als: sim! [Em coro]

23. P: Vocês também vão escrevendo, viu? Quem não escrever o bilhete a mãe não vai ficar sabendo, por que a mãe não é advinha, não é?

24. P: Bora ler... agora!

Mamãe, venha receber o material de seu filho! É só isso? [Algumas crianças dizem que sim, outras não.]

25. P: Quando, domingo?

26. Als: Não [Em coro]

27. P: Não pode ser domingo, não? Domingo tem aula?

28. Als: Não!!! [Em coro]

29. P: Sábado tem aula?

30. Als: Não!!!! [Em coro]

31. P: Então, tem que ser quando?

32. Als: Segunda-feira! [Em coro] 
[A professora retomou o registro no quadro e escreveu: Dia: segunda-feira] 33. P: Depois nós temos que botar o que? A mamãe pode vir de qualquer hora?

34. Als: Não [Em coro]

35. P: Nós vamos dizer que vai ser às $10 \mathrm{~h}$, porque é hora que estão vindo as outras turmas...é a hora que já passou o recreio e mamãe já pode pegar o material e levar vocês para casa, certo?

[retomou a escrita e registrou: segunda-feira às 10h.]

36. P: Olhem como escreve horas...

Agora, tem outra coisa, quem é que está dando esse aviso?

37. Als: A professora [Algumas crianças]

38. P: Sim, tem que botar aqui embaixo quem foi que mandou o aviso.

[Ela registrou... Professora Maria]

39. P: Olha aí, bem lindo!!!! Pronto, todo mundo escreveu?

As crianças registraram o bilhete no caderno conforme o apresentado abaixo:

Mamãe/Papai

Mamãe venha receber o material de seu filho (filha)

Dia- segunda-feira

Às 10:00h da manhã

Professora Maria

Findado o registro do bilhete, a professora observou os cadernos das crianças um a um, quando necessário fez algumas intervenções sobre a legibilidade explicitando que era condição necessária para que os pais compreendessem a mensagem do texto.

O diálogo que dá início a produção coletiva, turnos 1 ao 6, inicia-se com a professora informando às crianças sobre a necessidade da convocação (inicialmente da mãe) para a reunião a ser realizada com os pais do 3으 ano A uma vez que as reuniões estavam sendo realizadas com o atendimento individual das turmas da escola. Em seguida trata da decisão da maneira com a qual as mães seriam avisadas para a reunião, através do bilhete, indicada na resposta das crianças no turno 6 à pergunta realizada no turno 1. Ou seja, os alunos percebem a necessidade de uso da escrita para a comunicação com os pais, elemento constitutivo da cultura escolar. Toda comunicação entre a escola e os pais se dá por meio de textos escritos. Os turnos 1, 3, 5 e 7 evidenciam a perspectiva dialógica (BAKHTIN/VOLOCHINOV, 1995) da professora na mediação do processo de escrita do texto, incitando os alunos por meio de perguntas, convocando-os a participar do processo.

Do turno 7 ao 23 evidencia-se a definição dos interlocutores, que inicialmente seria a Periódico Horizontes - USF - Itatiba, SP - Brasil - e020005 
mãe, e após a discussão, passam a ser sinalizados no texto como mamãe/papai. Percebemos, também, que a professora se preocupa com a forma da escrita do texto ao perguntar "Então, $o$ que posso dizer aqui"? Tal constatação nos remete ao que afirma Geraldi (1997, p. 160) sobre uma das condições necessárias para a produção de texto: a necessidade do locutor se constituir como tal, "[...] enquanto sujeito que diz o que diz para quem diz (o que implica responsabilizarse, no processo, por suas falas)".

No turno 12 O que mais eu posso dizer nesse bilhete, quem pode me ajudar? Como é que eu digo?, a professora incentiva as crianças por meio de uma estratégia dialógica a perceberem aspectos relevantes que constituem o gênero e também amplia as possibilidades de participação das mesmas, quando escuta e leva em consideração a fala de um aluno: Mamãe, venha receber o material de seu filho!. A contribuição dada pelo aluno atende às características do gênero que está sendo produzido e é imediatamente apropriada pela professora, legitimando-a por meio de um discurso de autoridade, nos termos atribuídos por (BAKHTIN/VOLOCHINOV, 1995; BAKHTIN, 2010).

Com o intuito de checar se as crianças estão compreendendo o conteúdo do texto, questiona no turno 18: É isso mesmo? Ou tem mais alguma coisa...Já sei é bem para dizer que vocês estão trelosos. Porém, as crianças demonstram compreender o conteúdo do texto, quando afirmam em seguida: Não, é para pegar os materiais!

Quando questionou no turno 21: "É assim, C? Todo mundo concorda, né? Será que ela vai entender esse bilhete?", nos parece que a professora incentivou as crianças a perceberem a relação existente entre o conteúdo do gênero escrito e a compreensão do seu interlocutor. Geraldi (1997) evidencia que no ato da produção de textos, o professor pode construir-se como co-autor, apontando caminhos possíveis para o aluno dizer o que quer dizer considerando o interlocutor.

Quando a professora mencionou no turno 23 Vocês também vão escrevendo, viu? Quem não escrever o bilhete a mãe não vai ficar sabendo, por que a mãe não é advinha, não é?”, ela frisou a importância de se copiar o bilhete para o caderno, para que a comunicação por meio dele fosse efetivada, a fim de que os interlocutores (os pais) tivessem acesso à informação nele contida. A cópia, nesta situação, tem um significado diferente daquele que comumente se vê nas turmas de alfabetização. Copiar um texto produzido pelos alunos, com sentido, e não uma 
atividade mecânica proposta pela professora.

Do turno 24 ao 39 observamos a relação articulada entre o ato de escrever e o ato de ler no processo de apropriação da escrita. Ao solicitar a leitura do que já estava escrito no quadro no turno 24 Bora ler... agora, a professora retomou com as crianças o que foi registrado no quadro para que percebessem quais elementos ainda necessitavam ser explicitados no texto. Nos parece que a intenção da professora está vinculada à tentativa de revisar o texto junto com as crianças para aprimorá-lo, levando em consideração os elementos constitutivos do gênero produzido através da releitura do texto intrínseca ao processo de produção. O processo de revisão do texto aproxima esta situação da realidade social de uso da escrita fora da escola, quando a revisão é sempre um procedimento necessário na escrita de textos. "Por isso ao escrever um texto, dentro ou fora da escola, estamos continuamente realizando revisões durante o processo de produção do escrito e (re)planejando o que virá mais adiante" (BRANDÃO, 2006, p.124).

Por fim, a professora explorou mais um elemento constitutivo do gênero: a assinatura do bilhete. Um fato que chamou a nossa atenção, é que em todo o evento de produção coletiva, as crianças foram estimuladas a participarem e tiveram essa participação valorada pela professora, porém no momento final de identificação da autoria, é a professora quem assina o bilhete, como se o mesmo fosse resultado de uma produção individual dela própria, negando a autoria real que incluiria os alunos, como vemos no turno 38: Sim, tem que botar aqui embaixo quem foi que mandou o aviso. E registrou no quadro, no final do bilhete, Professora Maria.

Esperávamos uma marca na escrita que assegurasse que aquela produção tinha sido realizada coletivamente, por exemplo: um "assinado a turma", "os alunos da turma", "о 3ㅇano $A^{\prime \prime}$ e até mesmo uma assinatura conjunta de alunos e professora. Ao analisar esse fato, nos parece que predomina o discurso de autoridade (BAKHTIN/VOLOCHINOV, 1995) constitutivo da cultura escolar, na medida em que a mediação por perguntas ocorreu em todo o evento, mas esteve ausente no fechamento da discussão com a afirmação da assinatura da professora sem qualquer problematização. O registro da autoria foi feito sem qualquer consulta prévia às crianças. Dessa forma, na finalização da produção do texto ocorre o apagamento do locutor, do produtor do texto.

Outro fator que pode ter influenciado na decisão da professora de assinar o bilhete, pode 
ser atribuído ao conteúdo que nele foi abordado, da ordem escolar, com informações relativas a um encontro com objetivos escolares. Presumimos que, mediante às formalidades intrínsecas aos escritos destinados ao pais - circulares, boletins, solicitações de presença de familiares à escola (gêneros que atendem as necessidades específicas da escola) -, que são assinados por pessoas que representam as ordens hierárquicas da instituição (professores, coordenadores, gestores), as características referentes a esses gêneros foram deslocadas pela professora para a produção coletiva realizada.

Após a produção coletiva do bilhete, a professora foi além e promoveu uma discussão comparativa com um texto lido anteriormente pela turma, em 17 de fevereiro, uma carta pessoal, proposta de leitura no Livro Didático de Língua Portuguesa, página 12. Os diálogos a seguir exemplificam a interação com as crianças na discussão dos textos bilhete e carta.

1. P: Agora eu faço uma pergunta. Um bilhete é um texto grande ou textinho pequeno?

2. Als: Pequeno! [Em coro]

3. P: E aquele que é grande, que a gente leu no nosso livro? É uma, uma...

4. A: Texto!

5. P: Uma que a gente leu naquele livro, que tinha um envelope. O que é?

6. A: Uma carta!

7. P: Uma caaaarta!!!!! Isso mesmo, parabéns, Clara. E a carta tem mais assunto, não é? Lembram que a gente leu no livro? De quem era a carta que a gente leu, quem lembra? Quem sabe?

8. Als: Do coelhinho e da coelhinha!

[As crianças rememoram o remetente e o destinatário da carta, a tartaruga Charlô e o coelho Felpo].

9. P: Tá vendo que vocês lembram.... Então vejam, a carta que Charlô mandou para Felpo era uma página todinha do livro, não era, mas o bilhete, que a professora escreveu oh, disse tudo aqui. Será que a mamãe vai ficar convencida? A mamãe quando ler esse bilhete vai entender.

O trecho acima veicula a tentativa da professora em incentivar as crianças a compararem os gêneros: uma carta pessoal extraída da obra Eva Furnari e sugerida como leitura no LD de Língua Portuguesa e o bilhete produzido coletivamente. O LD é utilizado como uma referência a partir da lógica e dos dispositivos da própria prática e não como um recurso pedagógico a ser seguido, como bem já demonstrou MACEDO (2005). De início a professora questionou as crianças sobre as dimensões do bilhete, se se tratava de um "texto grande ou pequeno" e antecipou-se ao afirmar que o texto da carta era um texto "grande", o que fora lido no livro, e 
que teria mais "assunto", em relação ao bilhete escrito. Ela destaca marcas próprias de cada gênero, por exemplo a carta que deve ser enviada num envelope buscando utilizar uma linguagem mais acessível aos alunos.

Ainda no diálogo, a professora estabeleceu a comparação entre os interlocutores dos textos: no bilhete, os pais, e na carta pessoal, os personagens Charlô, uma tartaruga, e Felpo, um coelho. Continuou discutindo sobre as características dos mesmos, enfatizando o assunto neles contidos e a compreensão sobre os interlocutores, referindo-se ao bilhete, quando falou: Então vejam, a carta que Charlô mandou para Felpo era uma página todinha do livro, não era, mas o bilhete, que a professora escreveu oh, disse tudo aqui. Será que a mamãe vai ficar convencida? A mamãe quando ler esse bilhete vai entender?". Constatamos, na mediação da professora, a perspectiva dialógica no sentido apontado por Bakhtin/Volochinov (1979). O diálogo com os alunos foi a chave para a realização bem-sucedida do evento, para a apropriação do gênero bilhete pelas crianças, que atribuíram uma função social clara para a escrita.

\section{Considerações finais}

Nossas reflexões sobre um evento de letramento bastante comum nos anos iniciais do ensino fundamental tiveram por objetivo destacar uma forma dialógica de mediação da professora no trabalho com a língua escrita numa turma que está finalizando o ciclo de alfabetização. Entendemos que é preciso analisar o contexto em que as ações da professora são construídas e refletir sobre as razões que levam os professores a organizarem suas dinâmicas de trabalho. Chartier (2000), nos faz perceber o quanto é redutor analisar o que efetivamente é realizado pelo professor em sala de aula com base no paradoxo entre o que seria tradicional e/ou inovador. Mais do que julgar e avaliar a prática pedagógica, é importante compreender as razões que subjazem à prática docente, as influências dos aspectos socioculturais como por exemplo, a ausência de um suporte material adequado ao trabalho do professor.

O evento aqui analisado evidencia quão importante é o papel da escola no que diz respeito à mobilização de um ensino voltado às práticas de letramento que ultrapassem as dimensões do codificar e decodificar, para que os estudantes consigam fazer uso das ferramentas do ler e escrever em contextos sociais mais amplos. Dessa forma, ao pensarmos na 
leitura e na produção de textos na esfera escolar, urge refletirmos de que maneira a atribuição de sentidos a essas práticas podem ser trabalhadas no contexto da sala de aula. A professora em questão opta por uma perspectiva dialógica na mediação entre os alunos e a escrita, embora, em muitos momentos, fique evidente a presença do discurso de autoridade definindo os processos de ensino, como observamos na assinatura do bilhete enviado aos pais. Os resultados aqui discutidos indicam o quanto ainda precisamos avançar na compreensão das práticas de ensino a partir de uma imersão mais aprofundada na sala de aula, recorrendo a métodos e metodologias que permitam desvendar, com mais clareza, o cotidiano das práticas de ensino, desvendar as lógicas das práticas, o sentido atribuído à escrita pelos professores.

\section{Referências}

ANDRADE, R. M. B. L. Produção de textos escritos nos anos finais do ensino fundamental: A ação docente no Brasil e em Portugal. 2015. 338f. Tese (Doutorado em Educação) - Programa de Pós-graduação em Educação, Universidade Federal de Pernambuco, Recife, 2015.

BAKHTIN, M. (VOLOCHINOV). Marxismo e filosofia da linguagem. 1a ed. São Paulo: Hucitec, 1995.

BARTON, D. Literacy: an introduction to the ecology so written language. 1a ed.. OxfordUK/Cambridge: Blackwell, 1994.

BRANDÃO, A. C. P. A revisão textual na sala de aula: reflexões e possibilidades de ensino. In: LEAL, T.F.; BRANDÃO, A.C.P. (orgs.). Produção de textos na escola: reflexões e práticas no Ensino Fundamental. 1a ed. Belo Horizonte: Autentica, 2006. p.119-134.

BUNZEN, C. S. Os significados do letramento escolar como uma prática sociocultural. In: VÓVIO, C. ; SITO, L; GRANDE, P. (Org.). Letramentos: rupturas, deslocamentos e repercussões de Pesquisas em Linguística Aplicada. 1ạ ed. Campinas: Mercado de Letras, 2010. p. 99-120.

BUNZEN, C. S. Dinamicidade e eventos de letramento na sala de aula: reflexões sobre usos do caderno escolar. In: COLÓQUIO INTERNACIONAL LETRAMENTO E CULTURA ESCRITA, 5., 2014, Belo Horizonte. Anais [...] Belo Horizonte: UFMG, 2014, p.1-20.

CHAGAS, V. Eventos de letramento na escola integrada: uma perspectiva etnográfica. 2011. 165f. Dissertação (Mestrado em Educação) - Programa de pós-graduação em Educação, Universidade Federal de São João Del-Rei. São João Del-Rei, 2011. 
CHARTIER, A. M. Fazeres ordinários da classe: uma aposta para a pesquisa e para a formação. Educação e Pesquisa, São Paulo, v. 26, n. 2, p. 157-168, jul./dez. 2000.

COOK-GUMPERZ, Jenny et al. A construção social da alfabetização. 2. Ed. Porto Alegre: Artmed, 1991.

COSTA, V. A. Práticas de leitura em uma sala de aula da Escola do Assentamento: Educação do Campo em construção. 2010. 250f. Tese (Doutorado em Educação) - Programa de Pósgraduação em Conhecimento e Inclusão Social, Universidade Federal de Minas Gerais. Belo Horizonte, 2010.

CRUZ, F. A. M. Produção de texto na alfabetização: Análise de uma prática do primeiro ano do Ensino Fundamental. 2012. 165f. Dissertação (Mestrado em Educação) - Programa de PósGraduação em Educação, Universidade Federal de São João Del-Rei, 2012.

GERALDI. J. W. Portos de passagem. 4. ed. São Paulo: Martins Fontes, 1997.

GIRÃO. M. F.; BRANDÃO, A. C. P. Ditando e escrevendo: a produção de textos na Educação Infantil. In: BRANDÃO, A. C. e ROSA, E. C. (Orgs.). Ler e Escrever na Educação Infantil. 2. ed. Belo Horizonte: Autêntica, 2011. p. 45-64.

GÓES, M. C. R.; SMOLKA, A. L. A criança e a linguagem escrita: considerações sobre a produção de textos. In: ALENCAR, E. S. (org.). Novas contribuições da Psicologia aos processos de ensino e aprendizagem. 1a ed. São Paulo: Cortez, 1992. p.123-169.

GREEN, J.; DIXON, C.; ZAHARLICH. A etnografia como lógica de investigação. Educação e revista, Belo Horizonte, v. 42, p. 13-79, dez. 2005.

GUERRA, S. É. M. S. Produção coletiva de carta de reclamação: interação professoras/alunos. 2009. 251f. Dissertação (Mestrado em Educação) - Programa de Pós-Graduação em Educação, Universidade Federal de Pernambuco. Recife, 2009.

HEATH, S. B. Ways with words: language, life and work in communities and classrooms. Cambridge: Cambridge University Press, 1983.

KLEIMAN, A. (Org.). Os significados do letramento. 1a ed. Campinas: Mercado das Letras, 1995.

LEAL, T. F. Produção de textos na escola: argumentação em textos escritos por crianças. 2004. 425f. Tese (Doutorado em Educação) - Programa de Pós-Graduação em Educação, Universidade Federal de Pernambuco. Recife, 2004. 
MACEDO, M. S A. N. Interações nas práticas de letramento: O uso do livro didático e da metodologia de projetos 1a ed. São Paulo: Martins Fontes, 2005.

MARINHO, M. A criação de um neologismo e a construção de um conceito. In: MARINHO, M. Letramento e Cultura Escrita. 1a ed. Belo Horizonte: UFMG, 2010. p. 68-100.

SCRIBNER, S; COLE, M. The psichology of literacy. 1a ed. Cambridge: Harvard, University Press, 1981.

STREET. B. Literacy in theory and practice. 1a ed. Cambridge: Cambridge University Press, 1984.

STREET, B. Letramentos Sociais. 1a ed. São Paulo: Parábola, 2014.

VARELLA, V. F. A construção de autoria em situações de produção coletiva de textos na escola. 2013. 271f. Dissertação (Mestrado em Educação) - Programa de Pós-Graduação em Educação, Universidade Federal de Pernambuco. Recife, 2013.

Recebido em maio 2019.

Aprovado em dezembro 2019. 